\title{
Caracterização farmacognóstica dos Frutos de Cordia sellowiana Cham. e de Cordia myxa L. (Boraginaceae Jussieu)
}

\author{
Isabel Cristina Ercolini Barroso, ${ }^{1}$ Fernando de Oliveira*,1,2 \\ ${ }^{1}$ Fundação Municipal de Ensino Superior de Bragança Paulista, Faculdade de Ciências Biológicas, 12929-600 \\ Braganca Paulista-SP, Brasil, \\ ${ }^{2}$ Faculdade de Ciências Farmacêuticas, Universidade de São Paulo, Av. Lineu Prestes, 580, \\ 05508-900 São Paulo-SP, Brasil
}

\begin{abstract}
RESUMO: Os frutos de Cordia sellowiana Cham. e Cordia myxa L. utilizados como emolientes demulcentes, béquicos e expectorantes foram estudados morfológico-anatomicamente, visando sua caracterização farmacognóstica. Foram fornecidos subsídios à identificação destes órgãos vegetais no estado natural e quando transformados em droga. A abordagem fitoquímica realizada permitiu por em evidência a presença de alcalóides, flavonóides, taninos e mucilagens. Em decorrência da presença de mucilagens, foi determinado o índice de intumescência dos frutos.
\end{abstract}

Unitermos: Cordia sellowiana, Cordia myxa, caracterização farmacognóstica.

\begin{abstract}
S: "Pharmacognostic diagnosis of fruits of Cordia sellowiana Cham. and Cordia myxa L. (Boraginaceae Jusssieu)”. The fruits of Cordia sellowiana Cham. and Cordia myxa L. utilized like emollients, demulcents, antitussive and expectorants have been morphological and anatomically studied aiming the pharmacognostic diagnosis. Subsides have been offered to the identification of the vegetable organs in nature and as crude drug. Phytochemical screening detected the presence of alkaloids, flavonoids, tannins and mucilages. Due to the existence of mucilages the intumescence index of the fruits has been determined.
\end{abstract}

Keywords: Cordia sellowiana, Cordia myxa, pharmacognostic characterization.

\section{INTRODUÇÃO}

C. sellowiana e C. туха pertencem a família Boraginaceae Jussieu difundida especialmente nos trópicos e nas regiões temperadas do mundo. Segundo Barroso (1986), no Brasil a família esta representada por poucos gêneros com espécies indígenas. Os gêneros Cordia L., Borago L., Pulmonária L., Heliotropium L. e Symphytum L., são importantes por incluírem espécies medicinais (Saito, 1984; Agra et al., 2007; 2008).

Cordia é mencionada por Pio Correa (1952), por ser produtor de substâncias empregadas como medicamentos e por inúmeras de suas espécies apresentarem usos medicinais. Saito (1984), estudando Cordia ecalyculata Vell, espécie medicinal cujas folhas transformadas em droga são comercializadas sob o nome de chá-de-bugre e de porangaba, aponta inúmeras outras espécies do gênero como úteis no tratamento de enfermidades Saito \& Oliveira (1986) efetuaram a morfodiagnose da droga elaborada com as folhas dessa espécie e Saito et al. (1985) indicaram nela a presença de alantoina.

Cordia verbenaceae A.DC conhecida como erva balieira e por salicina empregada como antiinflamatória e como anti-reumática, tem merecido a atenção de diversos pesquisadores (Akisue et al., 1983; Lins et al.,
1990; Sertie et al., 1988; 1990; Biavatti et al., 2007), são autores que estudaram esta espécie vegetal sobre características diferentes ligadas ao seu uso medicinal.

Ercolini Barroso (2002) menciona o uso dos frutos de C. туха L., como adstringente, antihelmíntico, demulcente, diurético e expectorante. Segundo esta mesma autora os frutos de C. sellowiana tem propriedades semelhantes à espécie anteriormente citada. Os frutos dessas duas espécies, principalmente em função do seu conteúdo em mucilagens, são utilizados na elaboração de xaropes com propriedades, demulcente, expectorante e béquica. Estes frutos são ainda empregados como alimento tanto de humanos como de animais. Destarte os de C. myxa são consumidos in natura quando maduros e em forma de conserva, convenientemente condimentada, quando ainda verdes.

Já os frutos de $C$. sellowiana são encontrados à venda, como medicinais, em mercados e em bancas de raizeiros ao Sul de Minas Gerais, no Circuito-dasÁguas. São vendidos maduros in natura, ou após processo de secagem, sendo conhecidos como mata fome, juretê, capitão-do-mato (Pio Correa, 1952), cháde-bugre, louro-mole, louro, catuteiro branco, capitãodo-campo (Lorenzi, 2000).

Este trabalho tem como objetivo contribuir para o melhor conhecimento dos frutos das duas 
espécies utilizadas por suas propriedades medicinais e édulas, fornecendo dados que permitam efetuar sua caracterização farmacognóstica.

\section{MATERIAL E MÉTODOS}

Os frutos destinados ao estudo tiveram origem em populações das espécies localizadas nas seguintes cidades:

C. sellowiana: coletados na cidade de Vargem (SP) em altitude entre 800 a $900 \mathrm{~m}$ a $22^{\circ} 55^{\prime} 11^{\prime \prime} \mathrm{S}$ e $46^{\circ} 24^{\prime} 42^{\prime \prime} \mathrm{W}$ e em Rio Claro Campus da UNESP a aproximadamente $650 \mathrm{~m}$ de altitude e $22^{\circ} 22^{\prime} 36^{\prime}$ 'S e $47^{\circ}$ $28^{\prime} 30^{\prime \prime} \mathrm{W}$. Exicatas deste material acha-se depositado no herbário da UNESP de Rio Claro sob a seguinte especificação HRCB 32.789 coletor Ercolini Barroso s/n.

C. туха: coletada em Rio Claro (SP) em altitude de aproximadamente $650 \mathrm{~m}$ a $22^{\circ} 22^{\prime} 36^{\prime \prime} \mathrm{S}$ e $47^{\circ} 28^{\prime} 30^{\prime} \mathrm{W}$, onde diversos exemplares desta espécie são cultivados. Exemplar vivo, existente no horto do departamento de botânica de Rio Claro identificado por comparação com exsicata depositada no herbário do Instituto de Botânica de São Paulo. SP. 7390.

Morfologia externa dos frutos: Os estudos organográficos das duas espécies foram realizados, utilizando-se materiais frescos, recém coletados levados ao laboratório em sacos plásticos e examinados no máximo após quatro horas de colheita. As características morfológicas dos frutos maduros foram obtidas a partir de 50 unidades de cada uma das espécies provenientes se seis indivíduos. Para a determinação do diâmetro dos frutos foi utilizado um paquímetro e para determinação do peso, balança analítica. Em todos os casos foram determinados a media e o desvio padrão.

Morfologia interna ou anatomia: frutos em diversos estágios de desenvolvimento foram estudados, sendo executados cortes transversais e longitudinais. Os cortes foram corados com safrablau com azul de toluidina $0,05 \%$ em tampão acetato $\mathrm{pH} 4,7$ ou por dupla coloração pelo Azul de Astra safranina (Roeser, 1972). As fotomicrografias foram obtidas em microscópio Carl Zeiss modelo MC-100 usando-se filme colorido ASA 50 .

Reações genéricas de identificação de classes de substâncias: Estes ensaios foram realizados com os frutos inteiros desenvolvidos e submetidos à secagem e a seguir moídos transformando-os em pó semi fino segundo Farmacopéia Brasileira. Foram efetuados testes para a verificação da presença das seguintes classes de substâncias: alcalóides, antraderivados, saponinas, flavonóides, taninos, esteróides e triterpenóides, cumarinas, óleos essenciais e mucilagens. Estes testes seguiram as especificações de Costa (1972) e Xorge, (1973). As mucilagens foram ainda avaliadas através do índice de intumescência segundo Costa, (1972).

\section{RESULTADOS}

\section{Cordia sellowiana}

Os frutos (Figs.1 a 5) são providos de epicarpo membranáceo, mesocarpo suculento e mucilaginoso e endocarpo pétreo. Quando plenamente desenvolvidos possuem forma elipsóide ligeiramente assimétrica (Fig.3) e são providos de vestígios de estilete (Figs.11, 14 e 17) localizados em uma pequena reentrância. Apresentam, quando maduros coloração que varia do amarelo ao acastanhado e são glabros e luzidios. O cálice é persistente (Fig.3) e permanece aderido ao fruto durante todo o seu desenvolvimento. As sépalas apresentam-se recobertas por indumento puberulento (Figs.11,14 e 17). As figuras 11 a 19 possibilitam a observação dos vestígios do estilete, do estigma, do cálice persistente e da semente em frutos inteiros e em secção transversais e longitudinais.

Os frutos de C. sellowiana são do tipo drupóide nuculâneo. Medem 1,67 cm $\pm 0,184 \mathrm{~cm}$ de diâmetro e pesam 3,9 g $\pm, 1,08 \mathrm{~g}$, variando respectivamente: diâmetro entre $1,2 \mathrm{~cm}$ e $2,05 \mathrm{~cm}$.

Durante o seu desenvolvimento, o eixo determinado pelo ponto de inserção do estilete e o local de fixação do pedúnculo sofrem inclinação de cerca de $35^{\circ}$.

O endocarpo do fruto apresenta-se firmemente aderido ao tegumento da semente constituindo o pirénio. Este conjunto apresenta forma arredondada achatada em relação ao seu eixo maior. O endocarpo é provido de rugosidade e de duas projeções apicais (Fig. 20 e 21), sendo uma delas bem mais evidentes. A figura 22 mostra a semente germinando através de fenda longitudinal.

\section{Cordia myxa}

Os frutos (Fig. 6 a 10) apresentam forma globosa e simétrica, são providos de vestígio de estilete localizados no ápice em uma ligeira reentrância. Apresentam quando maduros (Fig. 8) coloração que variam do amarelo pálido ao alaranjado. São providos de epicarpo membranáceo, mesocarpo suculento e mucilaginoso e endocarpo pétreo. O cálice é persistente e permanece aderido ao fruto durante todo seu desenvolvimento (Fig. 6, 7 e 8).

As figuras 6 a 8 representam o fruto em diversos estágio de seu desenvolvimento inteiro e em seç̧ões transversal e longitudinal. As figuras 23 a 31 mostram frutos em diversos estágios de desenvolvimento inteiros e em secções transversais e longitudinais.

Os frutos de C. myxa quando maduros apresentam diâmetro médio de $1,43 \mathrm{~cm} \pm 0,06 \mathrm{~cm}$ variando entre $1,63 \mathrm{~cm}$ e $2,34 \mathrm{~cm}$ considerando-se um universo amostral de 50 frutos.

O peso da matéria fresca corresponde ao valor médio $1,80 \mathrm{~g} \pm 0,32 \mathrm{~g}$ com um mínimo de $1,04 \mathrm{~g}$ e um 
máximo de 2,54 g.

O endocarpo pétreo contendo a semente aderida a ele - pirênio - possui forma globosa e elíptica e apresenta duas reentrâncias uma em cada pólo (Figs. 32 e 33). Sua superfície é de coloração brancacente e nitidamente rugosa.

As figuras $9 \mathrm{e} 10$ mostram um corte longitudinal e transversal do fruto evidenciando bem, em seu interior, o endocarpo pétreo aderido a semente. As figuras 6 a 8 mostram um conjunto de frutos onde é possível observar o cálice persistente em forma de taça. As figuras $32 \mathrm{e}$ 33 mostram a superfície rugosa do endocarpo pétreo provido de duas reentrâncias em sua extremidade. A figura 32 mostra ainda a linha que delimita a região por onde ocorre a geminação da semente.

\section{Anatomia dos frutos}

\section{Cordia sellowiana}

Secções transversais do ovário no inicio da diferenciação em fruto mostram estrutura tetralocular pelo desenvolvimento de tabique placentário (Figs. 34 e 35).

A epiderme externa (Fig. 36 ex) da folha carpelar é constituída por uma fileira de células de contorno retangular alongadas no sentido anticlinal. Esta fileira de células é recoberta por cutícula (Fig. 35 ct) fina e quando observada em secções paradérmicas apresentam contorno poligonal. Raros estômatos anomocíticos podem ser observados nesta região.

O parênquima fundamental ébem desenvolvido, sendo constituído por células isodiamétricas que deixam entre si espaços intercelulares do tipo meato. A região mais interna, em cada uma das duas folhas carpelares, envolve feixes vasculares colaterais (Fig. $35 \mathrm{fv}$ ) delicados entre os quais um se destaca pelo tamanho em relação aos outros, coincidindo ser o feixe vascular de maior calibre aquele localizado na região mais espessa da parede ovariana. O centro da estrutura é ocupado por um feixe vascular de maior calibre ladeado por outros de menor calibre. A epiderme interna da folha capelar é constituída por uma fileira de células de contorno retangular alongadas no sentido periclinal. (Fig. 35 ei)

Com o desenvolvimento do fruto algumas modificações vão se processando. No exocarpo de alguns frutos pode-se notar a presença de lenticelas (Fig. 40 le.). A região do mesocarpo vai ampliandose em decorrência de divisões celulares que ocorrem tanto no sentido periclinal como anticlinal (Fig. 40). As células localizadas mais externamente, nesta região, assumem o aspecto achatado. Outras localizadas um pouco mais internamente sofrem espessamento de lignina. As células do mesocarpo tratadas pelo Sudan IV adquirem coloração alaranjada indicando material lipofilo (Fig. 37)

Dos quatro lóculos ovarianos, três geralmente atrofiam terminando um só por se desenvolver, contendo no seu interior uma semente proveniente de óvulo anátropo.

As células do mesocarpo, situadas próximas ao endocarpo, adquirem tamanho bem maior que o das células localizadas mais externamente. As paredes celulares são finas, seu conteúdo intumesce em presença de água e coram-se intensamente pelo azul de metileno (Figs. 38, 39 e $40 \mathrm{~cm}, \mathrm{mi}$ ). As camadas celulares localizadas mais internamente em relação a esta última camada, possuem tamanho menor, associam-se ao endocarpo e sofrem conjuntamente um processo de lignificação envolvendo a semente e aderindo-se a ela (Fig. 40 en).

Assim, o fruto em desenvolvimento, ainda verde e medindo cerca de $1,0 \mathrm{~cm}$, apresenta epicarpo fino, liso e glabro. $\mathrm{O}$ mesocarpo pode ser dividido em duas regiões, uma mais externa e outra mais interna. $\mathrm{O}$ mesocarpo externo (Fig. 49 me) é constituído de cerca de 25 camadas celulares separadas do mesocarpo interno por uma faixa celular provida de células achatadas distribuídas por aproximadamente 12 fileiras celulares e que envolvem feixes vasculares. O mesocarpo interno (Fig. $40 \mathrm{mi}$ ) é constituído de 12 - 15 camadas de células grandes que se coram intensamente pelo azul de metileno. Seguem-se cerca de 12 camadas celulares menores adjacentes ao endocarpo e que sofrem processo de lignificação conjuntamente com esta região (Fig. 40 en)

O fruto plenamente desenvolvido caracterizase por apresentar grande quantidade de células mucilaginosas, algumas células de paredes lignificadas na região do mesocarpo externo e diversas camadas de células com paredes lignificadas localizadas junto ao endocarpo que também é pétreo e que envolve a semente. Bolsas contendo areia cristalina podem ser observadas na região do mesocarpo.

\section{Cordia myxa}

Secções transversais do ovário, no inicio de sua diferenciação em fruto, revelam estrutura bicarpelar, tetralocular, pelo desenvolvimento de tabique placentário (Figs. 41 e 42). O óvulo é anátropo e unitegumentado.

A epiderme externa da folha carpelar (Fig. 43 ex) apresentam-se constituída por celular de contorno retangular alongadas no sentido anticlinal. Esta epiderme é recoberta por cutícula fina. Quando vista em seção paradérmica apresenta contorno poligonal e incluem estômatos do tipo anomocítico.

O parênquima fundamental é bem desenvolvido sendo formado por células isodiamétricas que deixam entre si espaços celulares do tipo meato. Bolsas contendo areia cristalina podem ser observadas principalmente na região mais interna do parênquima fundamental, próximas aos feixes vasculares de posição central. 
O parênquima fundamental pode ser dividido em duas regiões. A mais externa é constituída por células de tamanho maior, com paredes um pouco mais espessadas e que se coram mais intensamente pelo azul de toluidina. A região mais interna apresenta células menores, de paredes mais finas e menos coradas pelo referido corante. A região central da estrutura possui um feixe vascular de tamanho maior ladeado por quatro outros menores, formando um conjunto cruciforme (Fig. 42).

A epiderme interna da folha carpelar que envolve os lóculos (Figs. 42 e 46 ei) é formada por uma fileira de células de contorno retangular e alongadas no sentido periclinal.

Com o desenvolvimento do fruto algumas modificações vão ocorrendo. Assim, em frutos com 6 a $8 \mathrm{~mm}$ de diâmetro as células da epiderme externa, principalmente em sua parede basal e tangencial externa, sofrem espessamento delicado que não se cora pela floroglucina clorídrica e se cora pouco pelo Sudan III. Raros estômatos podem ser observados nessa região (Fig. 43 es). A região do endocarpo vai ampliando-se em decorrência de divisões celulares tanto no sentido periclinal como no sentido anticlinal. As células do mesocarpo situadas mais externamente assumem aspecto achatado. O parênquima externo engloba, neste estágio, uma série braquiesclereides isolados ou agrupados (Figs. 43, 44 e $49 \mathrm{cp}$ ), que se coram intensamente em vermelho cereja pelo reativo de floroglucina clorídrica.

Nota-se, também, a presença de grande número de feixes de fibras. Na região mediana do mesocarpo observa-se a presença de feixes vasculares delicados acompanhados de fibras de lúmen largo e paredes pouco espessadas (Fig. $47 \mathrm{fv}$ ). A região do mesocarpo interior aos feixes vasculares, é constituída de células maiores que as outras e que intumescem na presença de água e se coram mais intensamente pela solução de azul de metileno (Fig. $45 \mathrm{~cm}$ ). As células da epiderme interna e as células do mesocarpo interior adjacente a elas se dividem em vários sentidos originando o endocarpo pétreo (Fig. $46 \mathrm{~cd}$ ).

\section{Testes de intumescência para mucilagens}

Os ensaios destinados a evidenciar a presença de mucilagem bem como sua correspondente caracterização forneceram os seguintes resultados, expressos nas Tabelas 1 e 2.

\section{Reações de identificação da presença de classe de substâncias}

A Tabela 3 mostra as reações genéricas indicativas de classes de substâncias presentes nos frutos de Cordia sellowiana Cham. e Cordia myxa L

\section{DISCUSSÃO E CONCLUSÕES}

De acordo com Fahn (1978), a separação do pericarpo em três camadas distintas serve para facilitar a descrição anatômica, sem, entretanto representarem tecidos separados do ponto de vista de sua origem. Este tipo de procedimento é utilizado por Oliveira \& Akisue (1991) na caracterização microscópica de drogas constituídas por frutos ou que contenham frutos na sua constituição.

Roth (1977), Spujt (1994) e Barroso et al. (1999) denominam de drupóide ao fruto que apresenta pericarpo nitidamente diferenciado em seu exo-meso e endocarpo. Neste tipo de fruto o exocarpo ou epicarpo funciona como uma camada protetora do fruto, o mesocarpo comumente tem consistência carnosa e o endocarpo pétreo ou percaminoso pode ter textura coriacea, ou lenhosa, com camadas esclerificadas que protegem a semente.

Os frutos tanto de $C$. sellowiana como de $C$. myха de acordo com Barroso (1999) são drupóides nuculânicos. Cortes transversais dos frutos em diversos estágios de desenvolvimento mostraram a presença

Tabela 1. Verificação da intumescência do fruto de Cordia sellowiana Cham. e do índice de intumescência (li) segundo Costa (1972).

\begin{tabular}{|c|c|c|c|c|c|c|c|c|c|}
\hline \multirow[t]{2}{*}{ Tubo $\mathrm{n}^{\circ}$} & \multirow{2}{*}{$\begin{array}{l}\text { Volume } \\
\text { Inicial } \\
\end{array}$} & \multicolumn{6}{|c|}{ Volume medido após } & \multicolumn{2}{|c|}{ Índice de Intumescência } \\
\hline & & $1 \mathrm{~h}$ & $2 \mathrm{~h}$ & $3 \mathrm{~h}$ & $4 \mathrm{~h}$ & $5 \mathrm{~h}$ & $20 \mathrm{~h}$ & $\left(\mathrm{li}_{4}\right)$ & $\left(\mathrm{li}_{20}\right)$ \\
\hline 1 & 4,0 & 5,1 & 5,1 & 5,0 & 5,0 & 5,0 & 6,1 & 1,25 & 1,52 \\
\hline 2 & 3,9 & 5,0 & 4,9 & 4,9 & 4,9 & 4,8 & 5,8 & 1,25 & 1,48 \\
\hline 3 & 4,0 & 5,3 & 5,2 & 5,1 & 5,0 & 5,0 & 5,9 & 1,25 & 1,47 \\
\hline 4 & 3,9 & 5,1 & 5,0 & 4,8 & 4,8 & 4,8 & 5,8 & 1,23 & 1,49 \\
\hline 5 & 4,0 & 5,2 & 5,2 & 5,0 & 5,0 & 5,0 & 5,9 & 1,25 & 1,48 \\
\hline 6 & 3,8 & 5,1 & 5,0 & 5,0 & 5,0 & 4,9 & 5,9 & 1,31 & 1,56 \\
\hline 7 & 4,0 & 5,1 & 5,0 & 5,0 & 5,0 & 4,9 & 5,9 & 1,25 & 1,48 \\
\hline 8 & 3,9 & 5,2 & 5,1 & 5,0 & 5,0 & 4,9 & 5,9 & 1,28 & 1,51 \\
\hline 9 & 3,2 & 5,2 & 5,0 & 4,9 & 4,9 & 4,8 & 6,0 & 1,53 & 1,87 \\
\hline 10 & 3,2 & 5,1 & 5,0 & 4,9 & 4,8 & 4,8 & 6,1 & 1,53 & 1,90 \\
\hline
\end{tabular}

$\left(\mathrm{li}_{4}\right)=$ após $4 \mathrm{~h} ;\left(\mathrm{li}_{20}\right)=$ após $20 \mathrm{~h}$. 
Tabela 2. Verificação da intumescência do fruto de Cordia myxa L. e do índice de intumescência (li) segundo Costa (1972).

\begin{tabular}{|c|c|c|c|c|c|c|c|c|c|}
\hline \multirow[t]{2}{*}{ Tubo $n^{\circ}$} & \multirow{2}{*}{$\begin{array}{l}\text { Volume } \\
\text { Inicial }\end{array}$} & \multicolumn{6}{|c|}{ Volume medido após } & \multicolumn{2}{|c|}{ Índice de Intumescência } \\
\hline & & $1 \mathrm{~h}$ & $2 \mathrm{~h}$ & $3 \mathrm{~h}$ & $4 \mathrm{~h}$ & $5 \mathrm{~h}$ & $20 \mathrm{~h}$ & $\left(\mathrm{li}_{4}\right)$ & $\left(\mathrm{li}_{20}\right)$ \\
\hline 1 & 3,4 & 4,8 & 5,0 & 5,0 & 5,0 & 5,0 & 5,4 & 1,47 & 1,59 \\
\hline 2 & 2,8 & 4,2 & 4,9 & 4,9 & 4,9 & 4,8 & 5,0 & 1,75 & 1,80 \\
\hline 3 & 3,2 & 4,8 & 5,2 & 5,2 & 5,2 & 5,0 & 5,0 & 1,62 & 1,56 \\
\hline 4 & 3,0 & 4,6 & 4,9 & 4,9 & 4,8 & 4,8 & 5,0 & 1,60 & 1,66 \\
\hline 5 & 3,4 & 5,0 & 5,4 & 5,4 & 5,4 & 5,3 & 5,6 & 1,60 & 1,65 \\
\hline 6 & 3,6 & 4,9 & 5,2 & 5,0 & 5,0 & 5,0 & 5,4 & 1,40 & 1,50 \\
\hline 7 & 3,8 & 5,0 & 5,4 & 5,4 & 5,4 & 5,2 & $S$ & 1,45 & S \\
\hline 8 & 3,6 & 4,9 & 5,4 & 5,2 & 5,2 & 5,2 & S & 1,44 & S \\
\hline 9 & 3,6 & 4,6 & 5,0 & 5,0 & 5,0 & 5,0 & S & 1,40 & S \\
\hline 10 & 3,8 & 4,8 & 5,1 & 5,0 & 5,0 & 5,0 & 6,1 & 1,31 & 1,37 \\
\hline
\end{tabular}

$\left(\mathrm{li}_{4}\right)=$ após $4 \mathrm{~h} ;\left(\mathrm{li}_{20}\right)=$ após $20 \mathrm{~h} ; \mathrm{S}$ = sobrenadente, leitura comprometida.

inicial de quatro lóculos (Figs. 34 e 43) que por aborto resultam em único lóculo no interior do qual se desenvolve uma única semente, raramente duas envoltas pelo endocarpo pétreo em estruturas plenamente desenvolvidas.

Tantos frutos de C. sellowiana como os frutos de C. туха são globosos de epicarpo liso e luzidio quando frescos e enrugado quando transformados em droga. Nas duas espécies o cálice é persistente. Em C. туха о cálice apresenta forma de taça e em C. sellowiana é campanulado e pentadenteado o que permite diferenciação desses dois frutos. Os vestígios de estilete e de estigma estão presentes nos dois tipos de frutos. Em C. sellowiana, durante o desenvolvimento, o eixo localizado entre o pedúnculo floral e a região estigmática sofre rotação de cerca de $45^{\circ}$ no que difere de C. туха.

C. sellowiana como C. туха apresentaram o pericarpo diferenciado em exo, meso e endocarpo. $\mathrm{O}$ exocarpo é constituído por uma só camada de células e o mesocarpo apresenta duas regiões distintas: uma região próxima ao exocarpo e a outra próxima ao endocarpo. A diferença entre estas duas regiões consiste no tamanho das células e nas substâncias produzidas especificamente. Fato semelhante foi observado por Saito (1984) para $C$. ecalyculata. O mesocarpo de C. sellowiana assim como o de C. туха apresentou crescimento em espessura por diferentes tipos de divisões celulares, fenômeno frequentemente observado para as drupas estudadas por Roth (1977).

Portanto, o crescimento e a forma dos frutos de C.sellowiana e de C. myxa deve-se provavelmente, a divisões celulares que ocorrem em todas as direções. Entretanto é possível observar o aparecimento de uma região mais interna do mesocarpo com intensas divisões periclinais em relação ao eixo maior dos frutos, consistindo ao que parece num meristema ventral, fato este melhor observado em $C$. sellowiana. Uma outra

Tabela 3. Reações genéricas indicativas de classes de substâncias presentes nos frutos de Cordia sellowiana Cham. e Cordia myxa L.

\begin{tabular}{|c|c|c|c|}
\hline Classe de Substâncias & C. sellowiana & C. myxa & Reações utilizadas \\
\hline Alcalóides & + & + & $\begin{array}{l}\text { Reativo de Mayer; Reativo de Dragendorf; Reativo de } \\
\text { Brouchardat; Reativo de Bertrand. }\end{array}$ \\
\hline Antraderivados & - & - & Reação de Borntraeger. \\
\hline Cumarinas & - & - & Reativo de NaOH; visualização UV. \\
\hline Esteróides & - & - & $\begin{array}{l}\text { Reação de Libermann; Reação de Salkowiski; Reação de } \\
\text { Linday. }\end{array}$ \\
\hline Flavonóides & + & + & $\begin{array}{l}\text { Reação de Wilson Talbodk (oxalobórica); Reação de } \\
\text { Shinoda; Reação de Cloreto de Alumínio; Reação de } \\
\text { Cloreto Férrico; Reação de Hidróxido de Sódio. }\end{array}$ \\
\hline Mucilagens & + & + & Intumescência e coloração de Azul de metileno. \\
\hline Óleos essenciais & - & - & $\begin{array}{l}\text { Pesquisa de odor aromático; Pesquisa de substâncias } \\
\text { lipófilas no hidrodeslilado (Sudan III). }\end{array}$ \\
\hline Saponinas & - & - & $\begin{array}{l}\text { Atividade afrogênica; Atividade hemolítica do estrato } \\
\text { aquoso isotonisado. }\end{array}$ \\
\hline Taninos & + & + & $\begin{array}{l}\text { Adstringência; Reação com acetato de cobre; Reação } \\
\text { sulfato de quinidina; Reação com cloreto férrico; Teste } \\
\text { de gelatina; Reação acetato básico de chumbo; Reação de } \\
\text { Wasicky; Reação com molibidato de amônia. } \\
\end{array}$ \\
\hline Triterpenóides & - & - & Reação Liebermann. \\
\hline
\end{tabular}




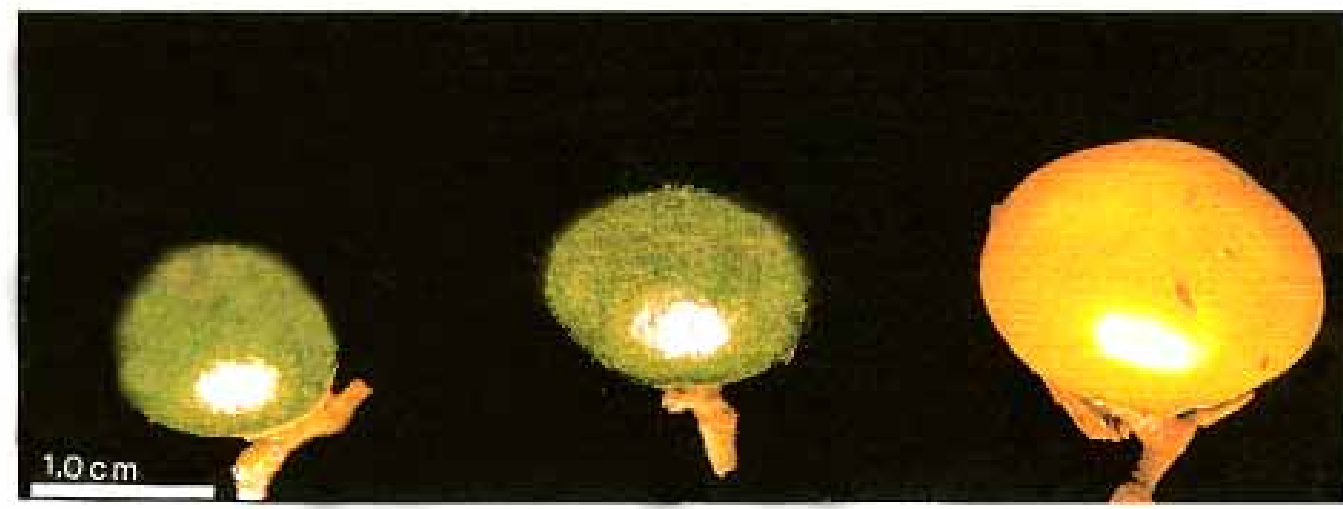

1

2

3

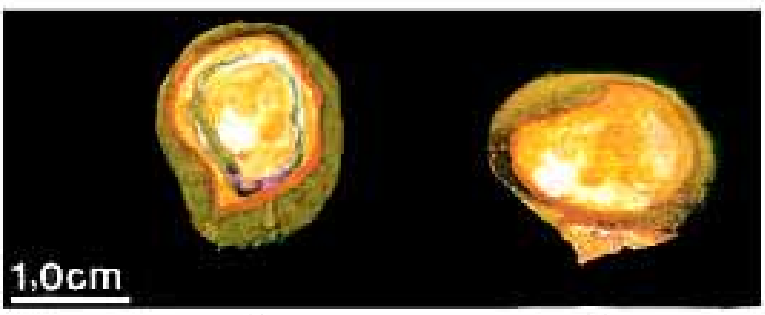

4

5

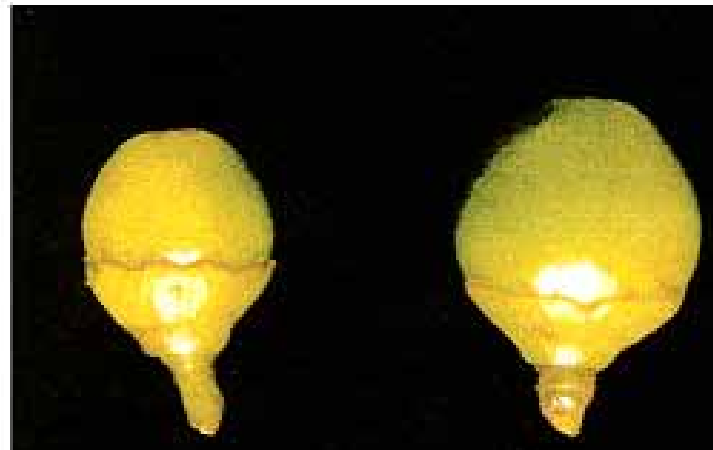

\section{$1.0 \mathrm{~cm}$}

6

7

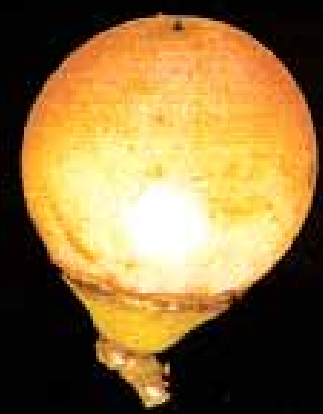

8

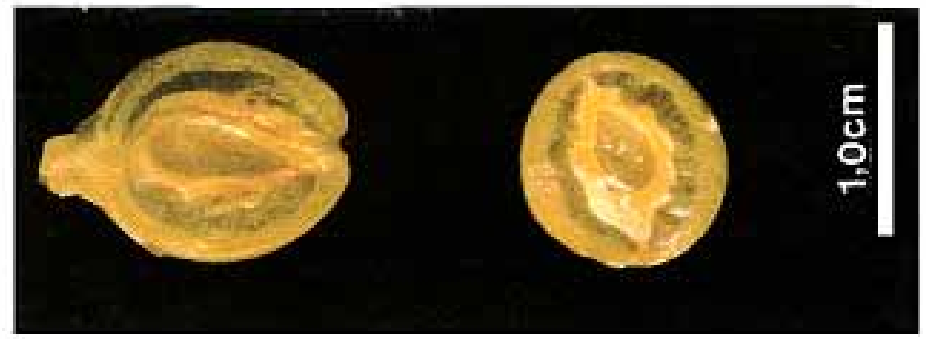

9

10

Figuras 1 a 10. Cordia sellowiana Cham. - 1 e 2 frutos jovens; 3 - fruto plenamente desenvolvido; 4 - corte longitudinal; 5 - corte transversal. Cordia myxa L. 6 e 7 - frutos jovens; 8 - frutos plenamente desenvolvido; 9 - secção longitudinal; 10 secção transversal. 


\section{Cordia sellowiana Cham.}
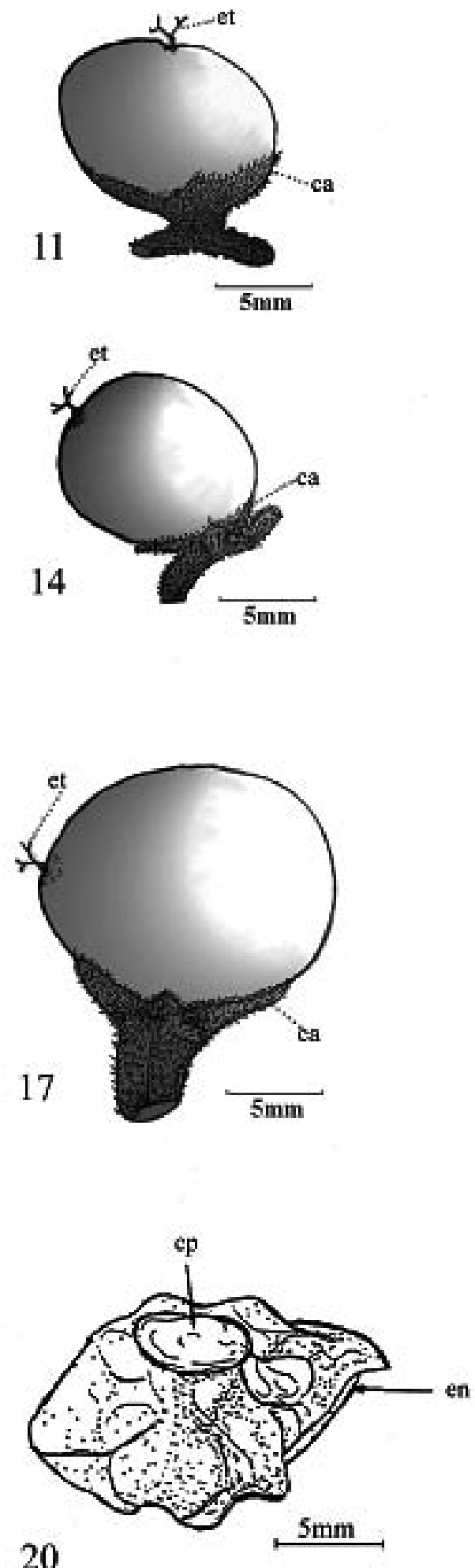
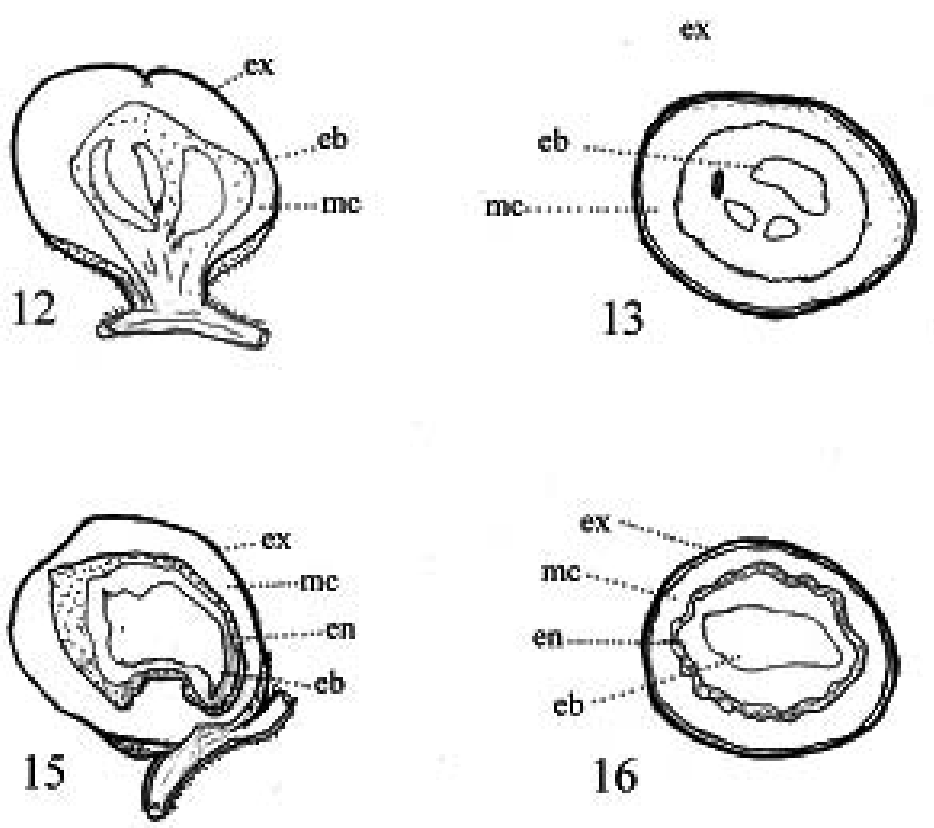

Figuras 11 a 22. Cordia sellowiana Cham. - 11, 14 e 17 frutos inteiros em estágios de desenvolvimento diferentes; 12,15 e 18 cortes longitudinais, 1316 e 19 - cortes transversais; 20, 21 e 22 pirênios. 


\section{Cordia myxa L.}
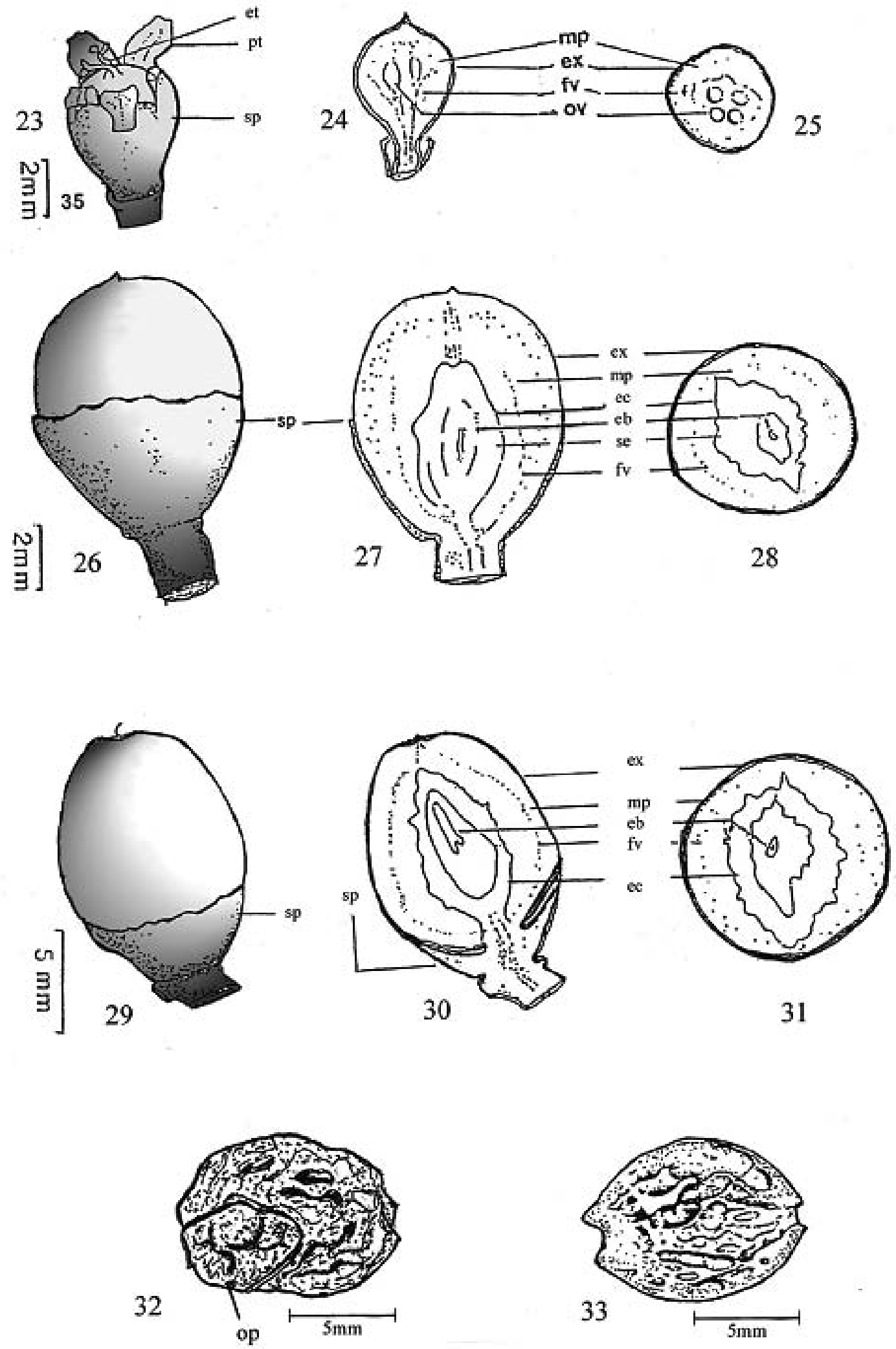

Figuras 23 a 33. Cordia myxa L. - 23, 24 e 25 - frutos inteiros em estágios de desenvolvimento diferente; 24,27 e 30 secções longitudinais; 25, 28 e 31 - cortes transversais; 32 e 33 pirênios. 


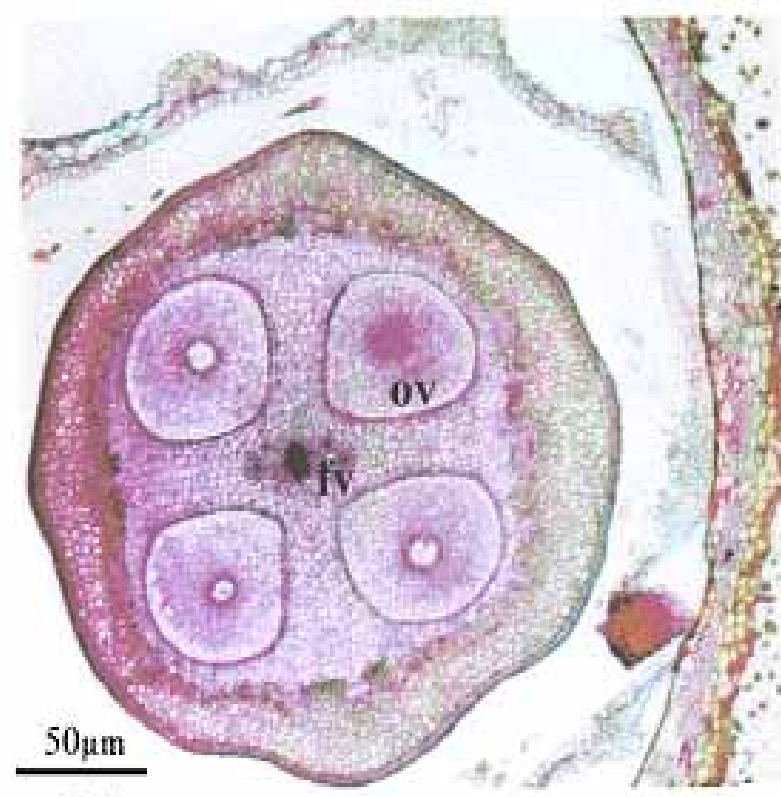

34

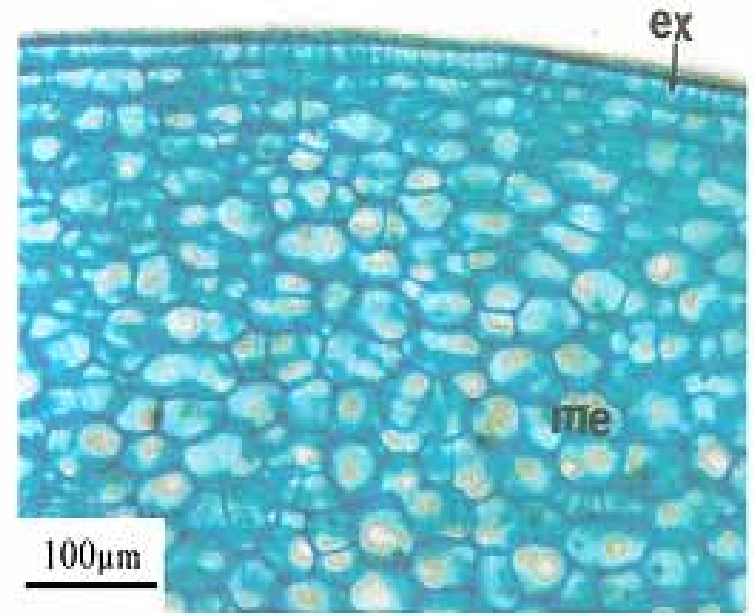

36

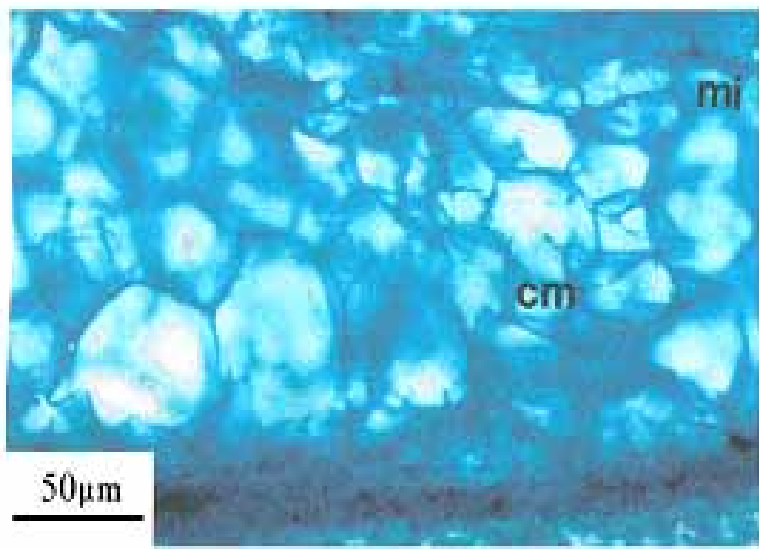

38

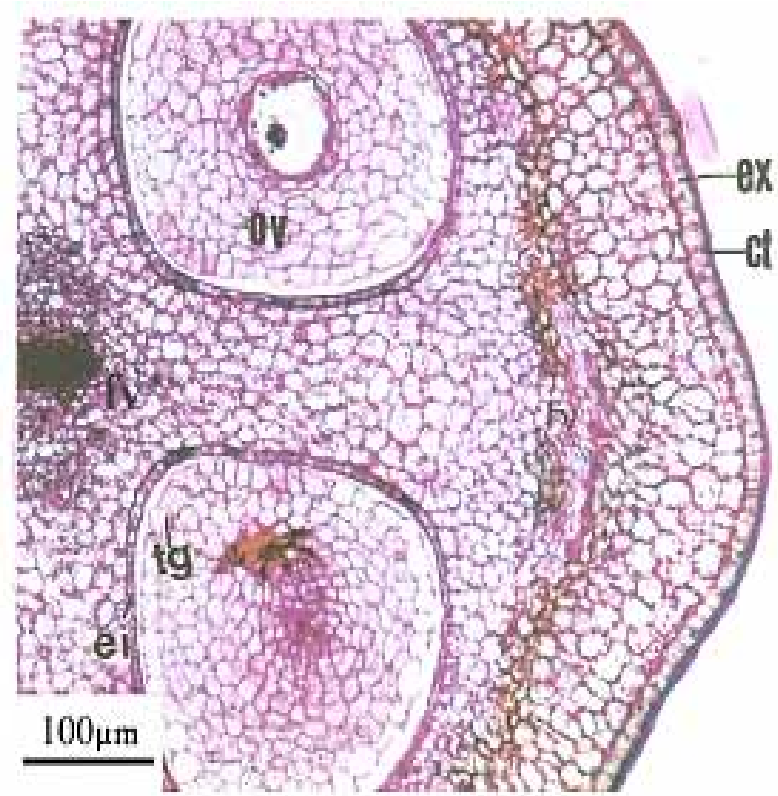

35
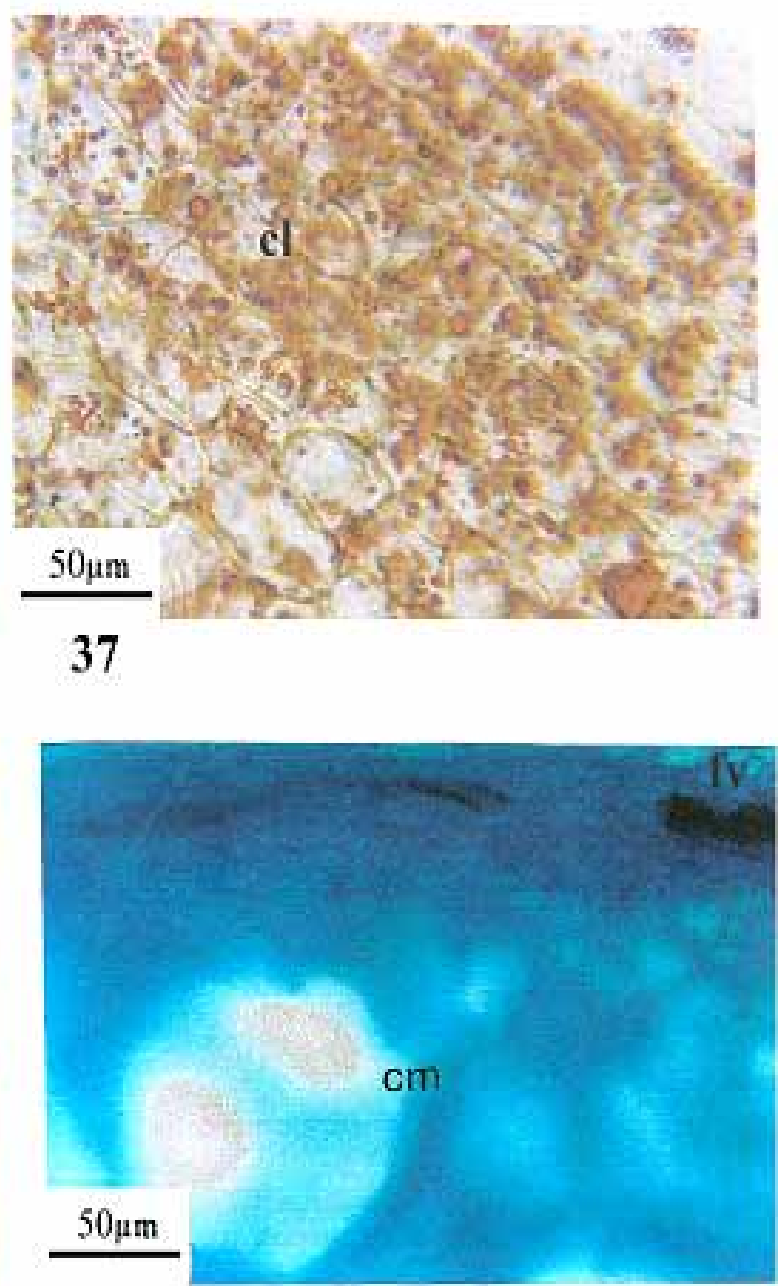

39

Figuras 34 a 39. Cordia sellowiana Cham. - 34 e 35 - corte transversal do ovário: ct. - cutícula; ei. - epiderme interna; ex. epiderme externa; tg. - tegumento do óvulo; f.v. - feixe vascular; ov. - óvulo. 


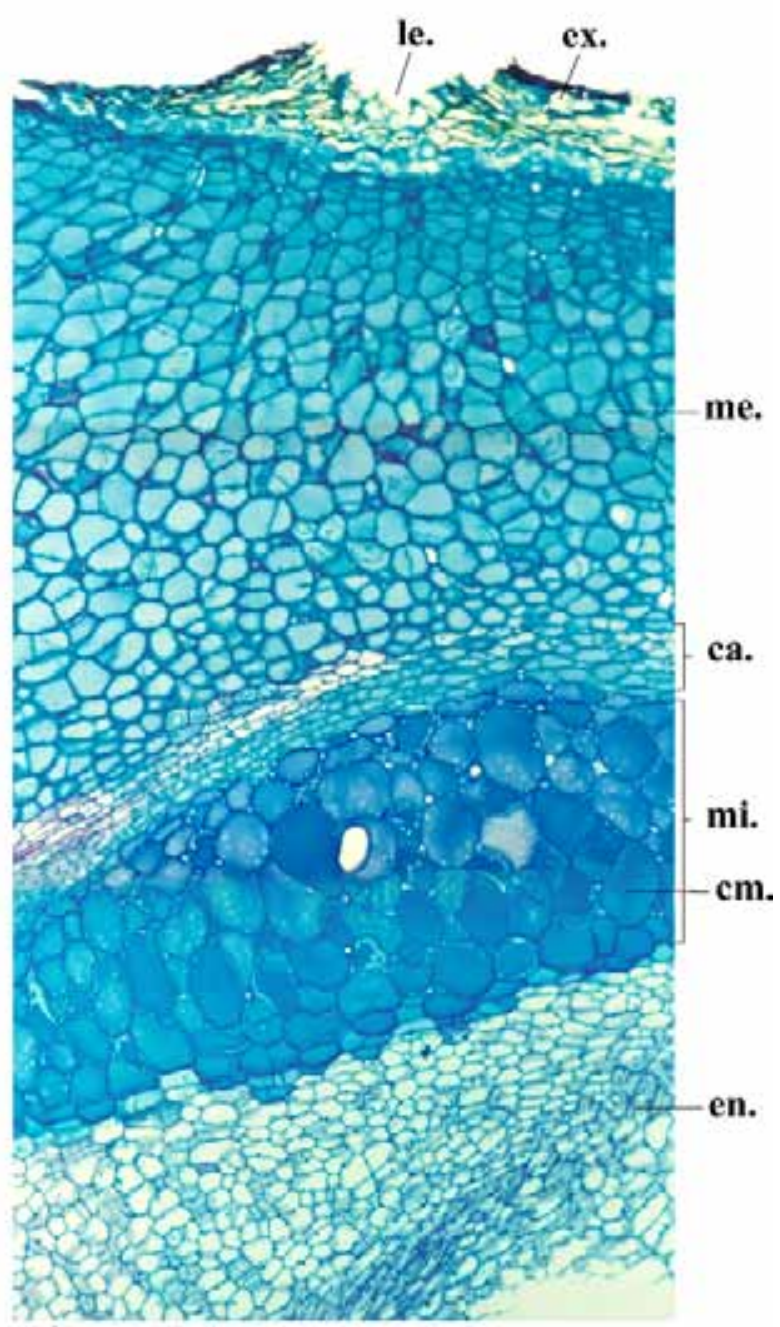

40

Figura 40. Cordia sellowiana Cham. - Secção transversal do fruto; le. - lenticela; ex. - epiderme externa; me. - mesocarpo externo; ca. - camada de células achatadas; mi. - mesocarpo interno; cm. - células mucilaginosas; en. - endocarpo.

região de intensa atividade de divisões periclinais é a que se forma na epiderme interna do ovário e que, mais tarde, dará origem ao endocarpo pétreo.

Frutos ainda imaturos de C. sellowiana com cerca de $0,9 \mathrm{~cm}$, apresentaram lenticelas esparsas, originadas da atividade de um "felogênio" que produz súber em direção ao exterior. Fato semelhante foi relatado por Mourão (1997) para Vismia guianensis no fruto jovem. Mauseth apud Mourão (1997) afirmou que o aparecimento de lenticelas pode ou não estar associado com o desenvolvimento de uma periderme. A ausência desta diferenciação está geralmente relacionada a um início de atividade mitótica do parênquima situado abaixo de um ou mais estômatos. Se os estômatos são raros, então as lenticelas originam-se pela atividade de "felogênios" espalhados que surgem a partir de células epidérmicas. Acredita-se que estas lenticelas, observadas nos frutos de C. sellowiana, estejam associadas a atividades mitóticas no parênquima abaixo dos estômatos.

Os frutos de $C$. sellowiana e $C$. туха são bastante semelhantes entre si. Como características importantes na diagnose das drogas à presença de células mucilaginosas bem evidenciadas pelo azul de metileno na região do mesocarpo interior. Esta característica esta presente nas duas espécies.

A presença de idioblastos contendo areia cristalina localizada principalmente nas proximidades dos feixes vasculares corresponde à característica igualmente presente nas duas espécies.

C. myxa se diferencia de $C$. sellowiana no que diz respeito a estrutura anatômica do mesocarpo pela presença de esclereides, de lúmen largo localizados, principalmente, na região próxima ao epicarpo. Estes braquiesclereides são bem evidenciados pela floroglucina clorídrica.

As mucilagens são polissacarídeos acídicos que aparecem como constituintes normais das células, as quais, quando ricas neste tipo de conteúdo, são denominadas de células mucilaginosas (Capasso et al. 2000). Este tipo de substância é freqüente em tegumentos de sementes e em pericarpos. Uma das características destas substâncias é intumescer em presença de água. Outra é a de absorver intensamente a solução de azul de metileno. Estas duas características, com freqüência são empregadas para detectar sua presença bem como para estimar a quantidade dela presente em órgão vegetais.

A presença de mucilagens é característica importante na identificação dos frutos tanto de $C$. sellowiana como de C. myxa. O conteúdo de mucilagem é maior em C. mуха que em C. sellowiana avaliada pelo índice de intumescência.

As mucilagens apresentam atividade emoliente estando provavelmente relacionadas com as propriedades béquicas e expectorantes dos frutos das duas espécies. Os conteúdos mucilaginosos permitem elaboração com eles, de xaropes com propriedades expectorantes e ao mesmo tempo demulcentes.

Com referência a substâncias do metabolismo secundário a presença de alcalóides nos frutos constituem características importantes que podem ser empregados como auxiliares na identificação da droga. A natureza química dos alcalóides presentes não é conhecida, ainda, constituindo assunto a ser investigado. A toxidade aguda também ainda não foi estudada correspondendo a outro assunto interessante a ser pesquisado. Sabe-se, entretanto, que os frutos maduros das duas espécies costumam ser forrageados intensamente pela megafauna. Os frutos de ambas as espécies costumam ser consumidos por humanos, o que pode ser evidência da sua baixa ou não toxidade.

Outra classe de substâncias importantes e presentes no metabolismo secundário de C. sellowiana e de C. туха são os flavonóides, ou seja, derivados do esqueleto da fenilbenzopirona. Esta classe de 

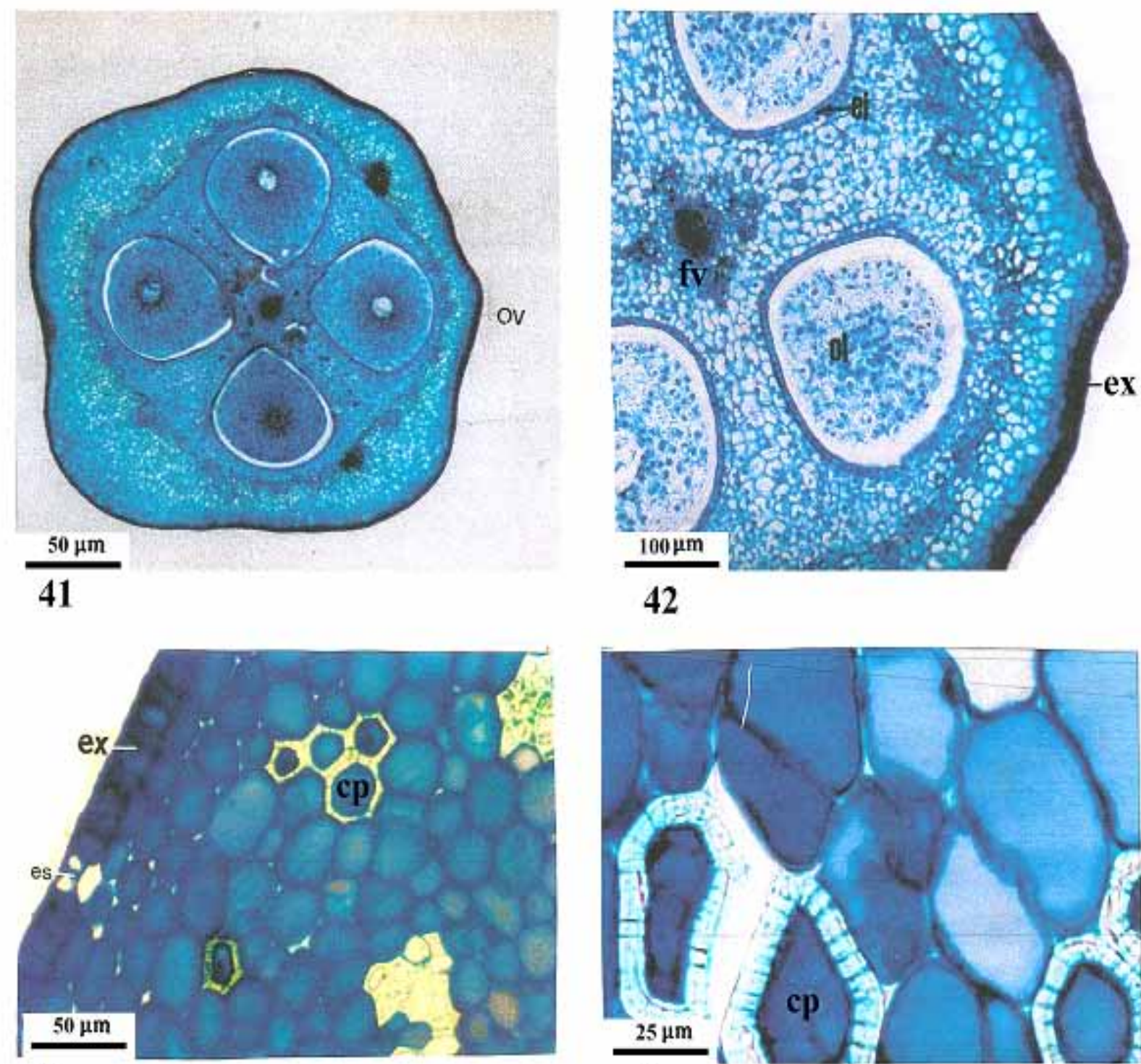

43
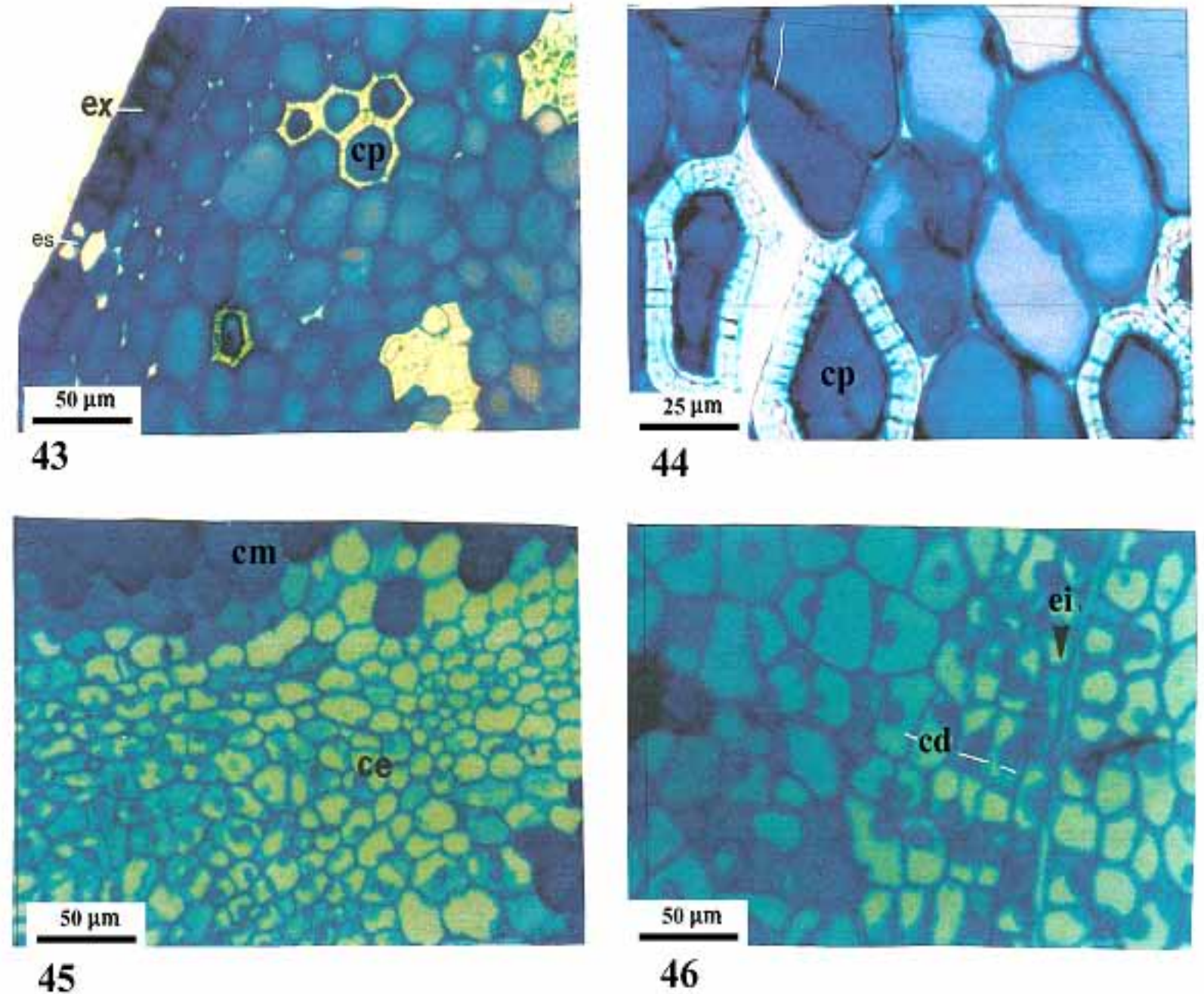

Figura 41 a 46. Cordia myxa L. - 41 e 42 - corte transversal do ovário; ct. - cutícula; ei. - epiderme interna; ex. - epiderme externa; tg. - tegumento do óvulo; f.v. - feixe vascular; ov. - óvulo. 


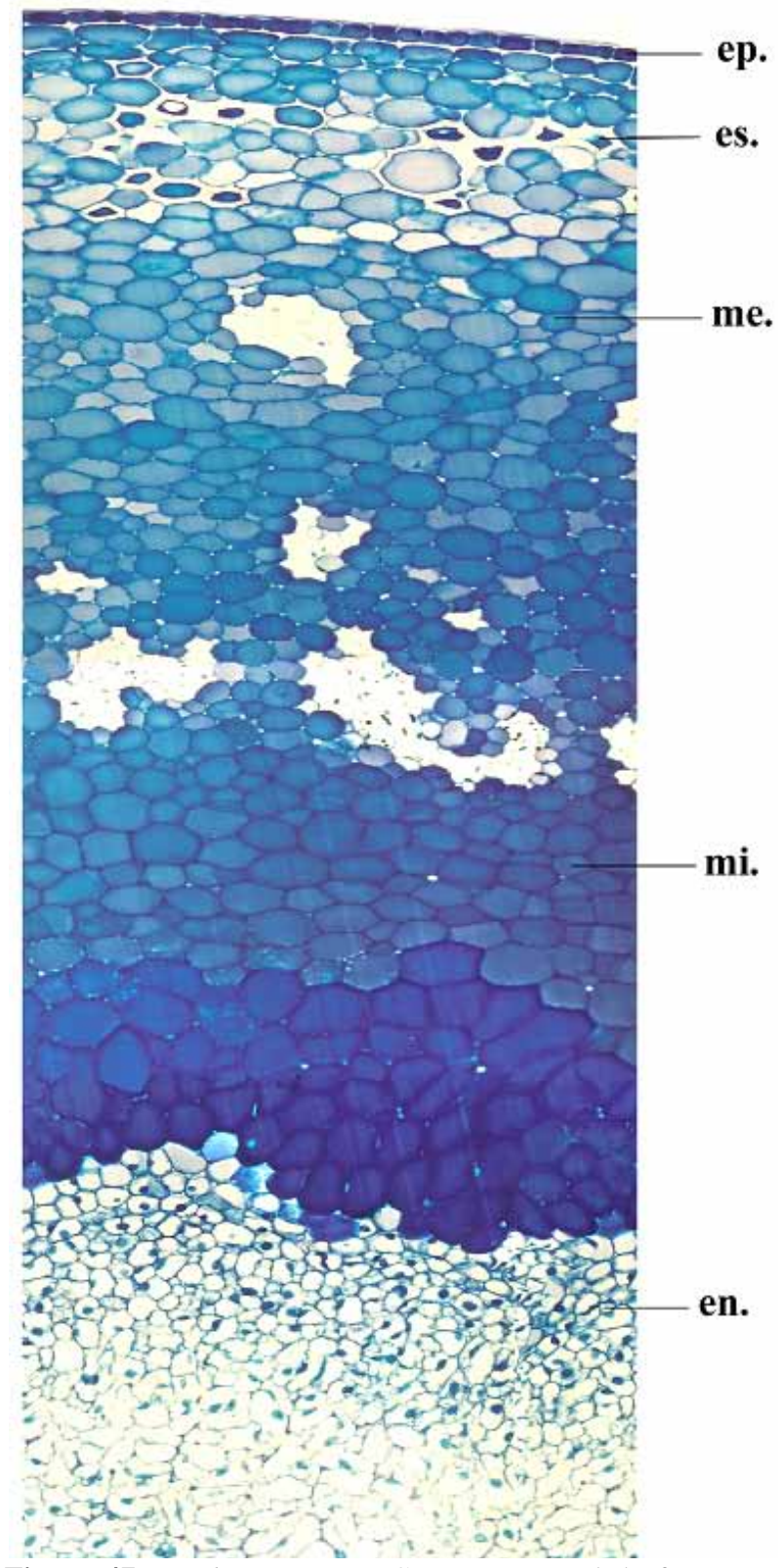

Figura 47. Cordia myxa L. - Corte transversal do fruto; ep. - epiderme; es. - esclereides; me. - mesocarpo externo; mi. mesocarpo interno; en. - endocarpo.

substâncias apresenta grande influência em alelopatia, estando frequentemente ligada a fenômenos de estabelecimento de plântulas em ambientes diversos. Os flavonóides na sua grande maioria são compostos fenólicos que reagem com o cloreto férrico, originando cor azul escura ou negra. São substâncias que por seu caráter fenólico apresentam frequentemente atividade bactericida (Kuklinski, 2000; Capasso et al. 2000).

Atribui-se ainda aos flavonóides uma serie de atividades tais como atividade antiinflamatória, analgésica, antioxidante, antivaricosa e como co-fator de vitamina $\mathrm{C}$.

Os frutos de C. sellowiana como os de C. туха reagiram positivamente para taninos.
Dos testes efetuados para detectar a presença desta classe de substância a verificação do sabor adstringente merece consideração especial. Sem duvida alguma, este teste biológico parecer ser aquele que serve como melhor indicativo dos taninos. Em contato com a boca os taninos precipitam proteínas da mucosa bucal e induzem vaso constrição sentida como um aperto na boca ou como sensação semelhante à de banana verde na boca. Os taninos são compostos de natureza fenólica polimérica que são capazes de transformar pele em couro, em outras palavras ligam-se de forma irreversível a proteínas.

Tanto C. sellowiana como C. myxa apresentaram reações negativas para a presença de glicósidos saponínicos, glicósidos cardiotônicos, óleos essenciais, cumarinas, antraderivados, esteróides e triterpenóides.

\section{REFERÊNCIAS}

Akisue MK, Oliveira F, Moraes MS, Akisue G, Mancini B 1993. Caracterização farmacognóstica da droga e da tintura de Cordia verbenaceae Al. DC Boraginaceae. Rev Ciênc Farm São Paulo 5: 69-82.

Agra MF, França PF, Barbosa-Filho JM 2007. Synopsis of the plants known as medicinal and poisonous in Northeast of Brazil. Rev Bras Farmacogn 17: 114-140.

Agra MF, Silva KN, Basílio IJLD, França PF, Barbosa-Filho JM 2008. Survey of medicinal plants used in the region Northeast of Brazil. Rev Bras Farmacogn 18: 472508.

Barroso GM 1986. Sistemática de Angiospermas do Brasil. Viçosa, UFV, p. 88-94.

Barroso MB, Morim MP, Peixoto AL, Ichaso CLF 1999. Fruto e Sementes, Viçosa, UFV, 79, 345 e 347.

Biavatti M, Marensi V, Leite SN, Reis A 2007. Ethnopharmacognostic survey on botanical compendia for potential cosmeceutic species from Atlantic Forest. Rev Bras Farmacogn 17: 640-653.

Capasso FPR, Grahdolini G, Mascolo N 2000. Farmacognosia - Farmaci naturali coro preparazioné ed imprego terapêutico. Milano, Springer Verlag, p.158-169.

Costa AF 1972. Farmacognosia. Lisboa, Fundação Colouste Gulbenkian, v.3, 1032p, ed. 2.

Ercolini Barroso IC 2002. Morfoanatomia da raiz, caule, folhas e frutos e desenvolvimento de plântulas de Cordia sellowiana Cham. e de Cordia myxa L. (Boraginaceae Jussieu). Dissertação de Mestrado UNESP. Rio Claro.

Ercolini Barroso IC, Oliveira F, Branco LHZ, Kato ETM, Dias TCO 2002. Gênero Cordia L.: botânica, química e farmacologia. Lecta 20: 15-34.

Fahn KE 1978. Anatomia vegetal. Madrid, H. Blume, 643p.

Kuklinski C 2000. Farmacognosia - Estudo das drogas y substancias medicamentosas de origen natural. Barcelona, ed. Omega, p.72-78.

Lins AP, Alvarenga MA, Gottlie OR, Oliveira F 1990. Two flavonols from Cordia verbenaceae. Rev Latinoamer Quim 21: 82. 1990.

Lorenzi H 2000. Árvores Brasileiras. Nova Odessa, Instituto Plantarum da Flora Ltda, 3 ed, v. 1, p. 72.

Mourão KSM 1997. Morfologia e desenvolvimento de frutos, sementes e plântulas de Vismia giranensis (Anebl.) Choisi e Mammea americana L. (Elusiaceae Lindley). 156 p. Tese (doutorado) UNESP, Rio Claro.

Oliveira FE, Akisue G 2003. Fundamentos da farmacobotânica. 
São Paulo, Atheneu, $178 \mathrm{p}$

Pio Correa M 1952. Dicionário das plantas úteis do Brasil e exóticas cultivadas. Rio de Janeiro. Ministério da Agricultura IBDF, v.3, p.312-313.

Pio Correa M 1969. Dicionário das plantas úteis do Brasil e exóticas cultivadas. Rio de Janeiro. Ministério da Agricultura IBDF, v.4, p.359.

Roth I 1977. Frui of Angiosperms. Encyclopedia of plant anatomy. Berlin Gebriider Brontraeger, v.1, 666p.

Roeser KR 1972. Dier nadel der schwar zkiefer massen product und Kunstwerk der nautr. Mikrokosmos 61: 33-36.

Saito ML 1984. Farmacognosia de Cordia ecalyculata Vell. (Boraginaceae). Dissertação de Mestrado, Pósgraduação em Fármaco e Medicamentos - Insumos Farmacêuticos FCF-USP.

Saito ML, Oliveira F, Alvarenga MA 1985. Alantoína e outros constituintes químicos de Cordia ecalyculata Vell. Rev Farm Bioq Univ São Paulo 21: 14-19.

Saito ML, Oliveira F 1986. Morfodiagnose e identificação cromatográfica em camada delgada de chá de bugre Cordia ecalyculata Vell. Rev Bras Farm 67: 1-16.

Sertie JAA, Basile AC, Panizza S, Matida AK, Zelnik R 1990. Anti-inflammatory activity and sub acute toxicity of artemetin. Planta Med 56: 36-40

Spujt RW 1994. A systematic treatment of fruit types. Mem N Y Bot Grad 70: 1-72, 1994.

Xorge AD 1973 Métodos de Investigação Fitoquímica. México, Editorial Limusa, 281p. 